\title{
STUDY OF THE INFLUENCE OF SOCIAL RELATIONSHIPS AMONG STUDENTS ON KNOWLEDGE BUILDING USING A MODERATELY CONSTRUCTIVIST LEARNING MODEL
}

\author{
FERNANDO ALONSO \\ DANIEL MANRIQUE \\ LOÏC MARTÍNEZ
}

Universidad Politécnica de Madrid

JOSÉ M. VIÑES

\begin{abstract}
The main objective of higher education institutions is to educate students to high standards to proficiently perform their role in society. Elsewhere we presented empirical evidence illustrating that the use of a blended learning approach to the learning process that applies a moderate constructivist e-learning instructional model improves students' academic outcomes. In this article, we use social network analysis techniques to analyze how social relationships improve student knowledge building with the deployment of this teaching/learning model. The results of this study suggest that the teaching/ learning model used promotes the social relationship of discussion and generation of new ideas, and this relationship has an impact on improving students' academic outcomes. We also illustrate that advice-seeking and trust among students are the relationships that most influence the discussion and generation of new ideas. We conclude by proposing learning strategies designed to improve these social relationships.
\end{abstract}


It is crucial to encourage individual and collective learning through knowledge building in the educational world. The leading challenge of a good education is to prepare students for a knowledge building culture. Knowledge building refers to the process of creating new cognitive artifacts as a result of common goals, group discussions, and synthesis of ideas. These pursuits should advance the current understanding of individuals within a group beyond their initial knowledge level and should be directed towards advancing the understanding of what is known about that topic or idea (Scardamalia \& Bereiter, 2003). Learning and knowledge building are similar but by no means identical concepts. Learning is designed to increase individual knowledge, whereas knowledge building is a social process that aims to continuously improve ideas as collective knowledge that adds to individual knowledge.

The learning process has evolved mainly in combination with the development of the three basic learning theories: behaviorism (Good \& Brophy, 1990), cognitivism (Anderson, 1996), and constructivism (Jonassen, 1991; Jonassen, Peck $\&$ Wilson, 1999). Since we consider that they are all potentially complementary, our moderate constructivist e-learning instructional model is supported by a blended view of these learning theories (Alonso, Lopez, Manrique \& Viñes, 2008): each theory inputs ingredients that are able to better explain how learning comes about.

From the learner's viewpoint, a number of specialists in learning theories (El-Deghaidy \& Nouby, 2008; Garrison \& Kanuka, 2004; Mornar \& Boticki, 2009; Thorne, 2003, advocate a blended learning solution (a b-learning approach)). Our moderate constructivist e-learning instructional model with a b-learning approach combines self-paced learning (Ellis, 2007), live e-learning (Stahl, 2005), and traditional classroom learning (Michell, 2001). The results of applying this moderate constructivist instructional model with a learning approach for teaching computer specialists (Alonso, Manrique \& Viñes, 2009) have been good. We have empirically confirmed that it reduces underachievement, and increases the number of students that feel they are well enough prepared to pass (Alonso, Manrique, Martínez \& Viñes, 2011).

Our goal now is to improve learning and academic outcomes by promoting knowledge building through the relationships among students that are most favorable to knowledge generation. Our teaching/learning method includes ingredients borrowed from constructivism and constructivist undercurrents like socialcognitive constructivism (Doise \& Mugny, 1984), social constructivism (Vygotsky, 1978), anchored instruction (Bransford, Sherwood, Hasselbring, Kinzer, \& Williams, 1990), social collaborative learning (Stahl, 2004) and learning communities (Palloff \& Pratt, 1999, 2003). Consequently, it is only logical that this educational model should encourage social relationships among students during the enactment of learning processes scheduled by the instructional model. These social relationships are worth researching. 
Many studies have demonstrated that social relationships play a decisive role in learning environments, where learning is the result of information exchange, joint task performance, conversations, and a network of social, cognitive, and emotional connections (Harasim, Hiltz, Teles \& Turoff, 1995; Haythornthwaite, 2002). The dynamics of these interactions is a factor of individual and collective knowledge building (Cohen \& Prusak, 2001; Nonaka \& Konno,1998). The idea that the nature of the interaction among students, their social relationships, has a notable influence or could even be a key factor explaining their achievement or abandonment of academic programs is widespread in education (Brass, 1984; Cho, Gay, Davidson, \& Ingraffea, 2007; Johnson \& Johnson, 1999). From this angle, learning is also described as a social relationship through which learners exchange, share, provide, and receive different experiences (Haythornthwaite, 2001). Learning is a predicate of interpersonal interaction (Haythornthwaite, 2008). In order to comprehend learning, then we have to understand the different patterns of interaction that are part of learning relationships (Skerlavaj, Dimovski, Mrvar, \& Pahor, 2010); the more interactions there are, the more people will learn from each other.

The core principle of knowledge building pedagogy is idea improvement through social interactions and processes. Accordingly, any educational program should promote iteration and discussion of new ideas (Bereiter \& Scardamalia, 2006). The discussion and generation of new ideas promotes knowledge building, and therefore learning.

The research questions addressed by this study are: a) Does our teaching/ learning method increase and strengthen the relationships of discussion and generation of new ideas among students? b) Does the discussion and generation of new ideas among students have any influence on their academic attainment? c) Are there any other social relationships that (positively) influence the discussion and generation of new ideas, knowledge building, or students' academic attainment?

In this article, therefore, we first empirically analyze the evolution of the social relationship of the discussion and generation of new ideas throughout the enactment of learning processes as part of an undergraduate course unit. Second, we examine how this social relationship influences the academic outcomes of students. Third, we show how the social relationships of friendship, communication and information exchange, advice-seeking, and trust influence the discussion and generation of new ideas. The ultimate aim is to discover which relationships our moderately constructivist teaching/learning model should promote in order to improve the individual and collective learning level of students and, consequently, their academic performance. Social network analysis (Wasserman \& Faust, 1994) provides very useful tools for studying the evolution, development, and influence of these social relationships. We ran this social network analysis on students of the 3rd-year, program development models (PDM) course unit. This course unit is 
taught using our teaching/learning method as part of the accredited 5-year informatics engineering degree program.

\section{OVERVIEW OF THE MODERATE CONSTRUCTIVIST INSTRUCTIONAL MODEL WITH A BLENDED LEARNING APPROACH}

Our teaching/learning method, which is a moderate constructivist instructional model (Alonso et al., 2009; Alonso et al., 2011) deployed as a b-learning teaching/ learning method, includes prescriptions and methods borrowed from different fields of knowledge.

The educational contents are structured on the basis of the concept of learning objective. A learning objective is the specific knowledge that the learner has to acquire about a concept or skill and the tasks to be performed. A learning objective is defined by a set of interrelated learning objects that each deals with a very specific item of knowledge (Alonso et al., 2008). Learning objects contain educational contents, a problem to be solved by a group that covers the concepts described in the educational contents (denoted as "good" problem), and exercises to assess student learning. A good problem is one that requires students to develop cooperative work, can be solved with inexpensive equipment, is realistically complex, benefits from group effort, and is seen as relevant and interesting by students. This structure is useful for developing coherent information structures that help to build knowledge schemata in the learner's mind (Donovan, Bransford, \& Pellegrino, 1999). Our method includes a collaborative environment, including activities designed to create a social environment that acts as a scaffold for collaborative learning and dialectical constructivism (Palloff \& Pratt, 1999, 2003). This instructional model maps the principles of moderate constructivism to the instructional design using emergent technology tools (Karagiorgi \& Symeou, 2005; Moreno, Gonzalez, Castilla, Gonzalez \& Sigut, 2005). It is composed of five phases: analysis, design, implementation, execution, and evaluation (Alonso et al., 2008; Alonso et al., 2009; Alonso et al., 2011).

Our blended learning process is enacted as a 15 -week course executed as follows:

1. The course kicks off with a 1-day face-to-face session where learners get the chance to meet each other and the instructor. The instructor presents the learning objectives, discusses the most significant knowledge and tasks to be learned, and describes the e-mail-, chat- and forum-mediated interactions.

2. Every week there is a 2-hour face-to-face session where students interact with the instructor, asking questions about the contents they have studied over the last week and discussing problems that they have encountered and possible solutions. The instructor presents the most important contents to be 
studied over the following week stressing the concepts that are most important or harder to learn.

3. One-hour interactions between learners and between learners and the instructor are held every week via chat or forums to consolidate and acquire knowledge. These are informal sessions, and their development is not structured. These sessions are especially important for students that were unable to attend the face-to-face session.

4. All students have a 1-hour group meeting supervised by the instructor to discuss any trouble that they have had with the "good problem" with regard to the educational contents that are being taught during the week. Groups meet independently in their own time and at their convenience to work on each good problem.

5. There is permanent e-mail support. E-mails should be answered within the following 24 hours.

6. Students have access to face-to-face support 6 hours per week. Learners can meet the instructor either individually or in groups to clarify contents and receive support on how to solve the good problems.

7. An online assessment is held every week, where students have to complete a 5-question questionnaire.

8. A final face-to-face assessment is held immediately after the course has finished. Students have to complete a 10 -question examination where they will be expected to complete short exercises on a common problem definition similar to the ones used in the good problems. The examination typically lasts $2 \frac{1}{2} 2$ hours. Learner assessment takes into account the scores achieved in this test, the solution of the weekly questionnaires, the solutions given to the good problems set throughout the course, and the learner's participation in live e-learning sessions.

\section{SOCIAL RELATIONSHIPS THAT SUPPORT LEARNING}

Interactions between members of an organization form continually evolving multi-relational networks. As part of this evolution, new networks appear or existing networks are modified. Obviously, people are linked by a wide range of relationships: friendship, information exchange, emotional support, rivalry, influence, hierarchy, parenthood, sex, trust, common interests, origin, etc. Some relationships take precedence over others depending on the goal in each setting. Organizational researchers have not only measured networks based on formal relationships, such as organizational work flows or hierarchy, but have also shown an interest in informal relationships, like advice-seeking, cooperation, support, and friendship (Lange, Agneessens \& Waege, 2004).

In the study reported in this article, we examine the social relationships of friendship, communication and information exchange, advice-seeking, trust, and discussion and generation of new ideas because they play a very important role in 
learning and knowledge building processes. Friendship is of great importance within educational environments (Baldwin, Bedell, \& Johnson, 1997) where the social relationships of friendship directly or indirectly provide access to information and knowledge (Baldwin et al., 1997) and thus boost knowledge building. Communication and information exchange among students is very important in higher education where it plays a key role in discussing and generating new ideas (Leenders, Engelen, \& Kratzer, 2003; Woodman, Sawyer, \& Griffin, 1993). Advice-seeking shows a positive correlation between a students' centrality in the advice-seeking network and their academic performance (Baldwin et al., 1997), and appears thus to have an important repercussion on knowledge building. Trust has a clear impact on the behavior of people in their social network (Chua, Ingram, \& Morris, 2008) and knowledge transfer (Levin \& Cross, 2004; McAllister, 1995). Finally, discussion and generation of new ideas throughout constructive feedback exchanges on creative task-focused ideas stimulate knowledge building and have a significant impact on creative processes (Amabile, Conti, Coon, Lazenby \& Herron, 1996; Zhou, 1998, 2008; Zhou \& George, 2003).

\section{Friendship}

Organizational researchers have had recourse to the relationships of friendship and communication because they are useful for studying and predicting results of great importance and interest regarding how network interaction patterns affect employee perceptions of work-related conditions (Ibarra \& Andrews, 1993).

Focusing on the relationship of friendship, people that are members of a network of friends maximize access to material and immaterial resources that are important for many life situations. Friendship offers psychosocial resources that provide emotional support for coping with adverse situations, positively enjoying and improving their satisfaction generally with what life has to offer (Ibarra, 1995; Baldwin et al., 1997).

In traditional learning environments, students that are at the centre of a social network of friendship have more prospects of receiving and offering help and, consequently, a bigger chance of learning more. Additionally, they have more access to positive relationships of emotional support, which are so important for coping with the stress of demanding educational programs (Ibarra, 1995).

\section{Communication and Information Exchange}

Communication and information exchange among groups of students are more instrumental than relationships of friendship and are much more focused on the exchange of information related to course contents. Being part of a network of communications in an academic setting is useful for identifying instructor practices, keeping up with course schedule changes, and, generally, being conversant with the many details required to perform successfully in a course (Baldwin et al., 1997). 
People need to combine information from many sources, exchange a lot of knowledge and multiple proposals. The raw material is ideas. Although they originate from one person, ideas require proper support to prosper. An idea cannot be developed, refined, tested, and implemented without effective communication among the members of an organization. Good communication is the basis for productive interaction. Ideas can be improved by means of consultation and interaction, where different viewpoints each contribute to their enrichment. The key to the development of innovative solutions, the outcome of new and creative ideas, is not so much individual genius as complex interactions within a group. This is a dynamic process where communication and information exchange reveal themselves as key components of the generative effectiveness of knowledge creation. Combination and exchange are key mechanisms for creating social knowledge, where information exchange is a prerequisite for resource combination (Nahapiet \& Ghoshal, 1998).

\section{Advice-Seeking}

Advice-seeking social relationships are built from interactions empowering people to share information, help, and guidance on questions related to job performance (Sparrowe, Liden, \& Kraimer, 2001).

These are instrumental rather than primary relationships. They are contextual relationships with more social and less situational connotations (Lincoln \& Miller, 1979). These relationships are a means for obtaining resources that are instrumental for improving job performance. A central position in an advice-seeking network indicates a person's involvement in the exchange of problem-solving resources.

A student with a central position in an advice-seeking network will have more information, knowledge, and experience for dealing with academic challenges and questions and will therefore be better equipped to perform more successfully in either the classroom or an online environment.

\section{Trust}

Trust is essential for rendering a collaborative, learning, creative, and innovative organization more effective. An aseptic exchange of just information will not do. People seeking help or advice from others that have information and knowledge are vulnerable, at risk of being considered inept, helpless, and thus dependent on the other person's authority.

Some authors consider that there must be trust before there is collaboration. Bradach and Eccles (1989) state that trust is an expectation of a sort that dismisses the fear of someone with whom we exchange something acting opportunistically. Behaviorally, collaboration implies exchange, resource sharing, and necessitates trust. Some researchers place trust at the heart of interpersonal relations (Burt, 2005; Granovetter, 1985). 
Trust can be divided into different types (i.e., affect-based and cognition-based trust) formed by different psychological processes. Levin and Cross (2004) have found that affect-based trust is higher in friendship networks or in networks with densely embedded ties, whereas cognition-based trust is higher in advice networks, and embeddedness has no effect.

Trust is dynamically and interactively developed, that is, gradually built up by means of interpersonal exchanges within groups and organization. It is a learning process among stakeholders, which includes emotional support, problem-solving assistance, and socialization. From this viewpoint, it is important to consider the relationship of trust among students in order to establish the influence of social relationships on academic outcomes.

\section{Discussion and Generation of New Ideas}

Knowledge building is based on teaching methods focusing on the generation and collective refinement of ideas (Scardamalia, 2002). In innovative organizations, any creative process is a highly social practice and involves interactions among people inside and outside the organization (Amabile, 1983; Perry-Smith \& Shalley, 2003; Woodman et al., 1993). The key process is the discussion and generation, and flow of new ideas in the interpersonal relationships of the group. Apart from being thought-provoking and stimulating, new ideas can be refined, assessed, and improved through discussion with other people. People that have more ties with different people are more creative as they are more likely to receive and share new information (Perry-Smith, 2006; Perry-Smith \& Shalley, 2003).

Because of the impact of this social relationship of idea discussion and generation on knowledge building, we have opted to study its evolution throughout the course, its effect on students' academic outcomes and how it is influenced by other social relationships: friendship, communication, advice-seeking, and trust. The aim is to observe which learning processes our teaching/learning method should promote in order to improve student learning and academic performance.

\section{METHOD}

One of the aims of this article is to study what influence social relationships among students have had on the improvement in their academic outcomes after the deployment of our moderate constructivist instructional model with a blended learning approach. We conducted this study during the 2011/12 academic year on students of the 3rd-year program development models (PDM) course unit, taught as part of the accredited 5-year informatics engineering degree.

We gathered subjective measures using two questionnaires that students completed at the start (pre-questionnaire) and at the end (post-questionnaire) of the course unit, just before the final examination. Preliminary instructions, explaining 
how students should complete the questionnaire, were followed by a total of five items in the pre-questionnaire and the post-questionnaire.

Students rated the questions in both questionnaires subjectively on a Likert scale, where the value 1 means "very low" and 5 means "very high." As the student group is large, it is unfeasible to ask each student individually about his or her relationships with all other network members. Instead, students were asked to rate their level of friendship (I1), communication (I2), advice-seeking (I3), trust (I4), and discussion and generation of new ideas (I5) with five fellow PDM students of their choice (most valued) for each of these questions at the start and end of the course unit. The use of the number five is usual practice in studies like these. These are the items:

- I1(pre), I2(pre), I3(pre), I4(pre), I5(pre): "Rate the level of friendship/ communication/advice-seeking/ trust/ discussion and generation of new ideas between you and the five fellow students with whom you interact most at present"; and

- I1 (post), I2 (post), I3(post), I4(post), I5 (post): "Rate the level of friendship/ communication/ advice-seeking/ trust/ discussion and generation of new ideas between you and the five fellow students with whom you interacted most during the course unit."

We have dichotomized the data collected in the pre- and post-questionnaires (I1, I2, I3, I4 and I5), with ratings on a 5-point Likert scale, transforming values 1 , 2 , and 3 to 0 ; and values 4 and 5 to 1 . This is a frequent transformation in research on social networks, as many of the measures and calculations with relational matrices are only available for dichotomized values in the most common social network analysis programs (Huisman, Kaiser \& Vossensteyn, 2003). These dichotomized matrices represent dichotomous networks.

To study the evolution of social networks with respect to the variables of friendship, communication, advice-seeking, trust, and discussion and generation of new ideas, we compared the final dichotomous networks (FDN) with the initial dichotomous networks (IDN), built from the dichotomized values of post- and prequestionnaires, respectively. We then built a differential dichotomous network (DDN) for each variable under study (friendship, communication, advice-seeking, trust, and discussion of new ideas), where each network node is a student, and a node is in-linked only when there is a difference greater than three between the Likert rating that the student received for the variable under study in the postnetwork (extracted from the post-questionnaire) and the respective initial network (calculated from the pre-questionnaire). Therefore, we considered positive differences greater than three between the scores of the post- and pre-questionnaires as a new tie or relationship in the evolution of social networks. This is the threshold used to dichotomize all the relationships. We did not take negative differences into account, as they are considered to be mostly due to students only being allowed to list relationships with five (most important) peers, where there may be 
relationships listed in the pre- and not in the post-questionnaire. Cyram (NetMiner) software was used for all the measures and analyses of the different social networks (NetMiner, 2012).

Figure 1 shows, from left to right, an illustrative abstract example of all of the networks used in the study to represent any specific social relationship of an imaginary student. The first graph is an initial network illustrating the relationships of this student with another five fellow students, gathered from the prequestionnaire. It is followed by the respective IDN. The next graph is the final network for the same student gathered from the post-questionnaire, followed by its respective FDN. The last graph represents the DDN network, calculated from the preceding FDN and IDN.

A total of 81 students participated in this study. This figure only includes students that took the course unit and completed both questionnaires. The gender distribution of students in the sample was approximately $62 \%$ male and $38 \%$ female. Respondents were, with very few exceptions, of the same ethnicity and of very similar ages, ranging from 20 to 23 years old. The same two teachers taught all students throughout the academic year. Analyzing the sample we found that students' previous education was not significantly biased, and ANCOVA was not necessary to validate the sample. This is consistent with students taking the same informatics engineering degree program.

\section{INFLUENCE OF THE PROPOSED B-LEARNING APPROACH ON THE DISCUSSION AND GENERATION OF NEW IDEAS}

To find out how our teaching/learning method influences the relationship of discussion and generation of new ideas and therefore knowledge building, we started by using the DDN to check that the initial network for this social relationship at the start of the course unit did not determine the generation of new ties in the final network. Second, we used the respective initial and final dichotomous networks (IDN and FDN) for the social relationship of discussion and generation of new ideas to analyze the evolution of the number of links and density of those networks, and how this relationship evolved in relation to other network members and group formation, both of which are techniques borrowed from social network analysis.

To check that the initial network for discussion and generation of new ideas at the start of the course unit did not determine the generation of new ties in the final network (and support the idea that the proposed teaching/learning method is the factor that influences the generation of new ties in the final network), we calculated the regression between the matrix representing the DDN (the new ties) and the matrix representing the IDN, where the new ties received by each student are the dependent variable for the social network of idea discussion and generation. They are the ties where the difference in the rating between the 


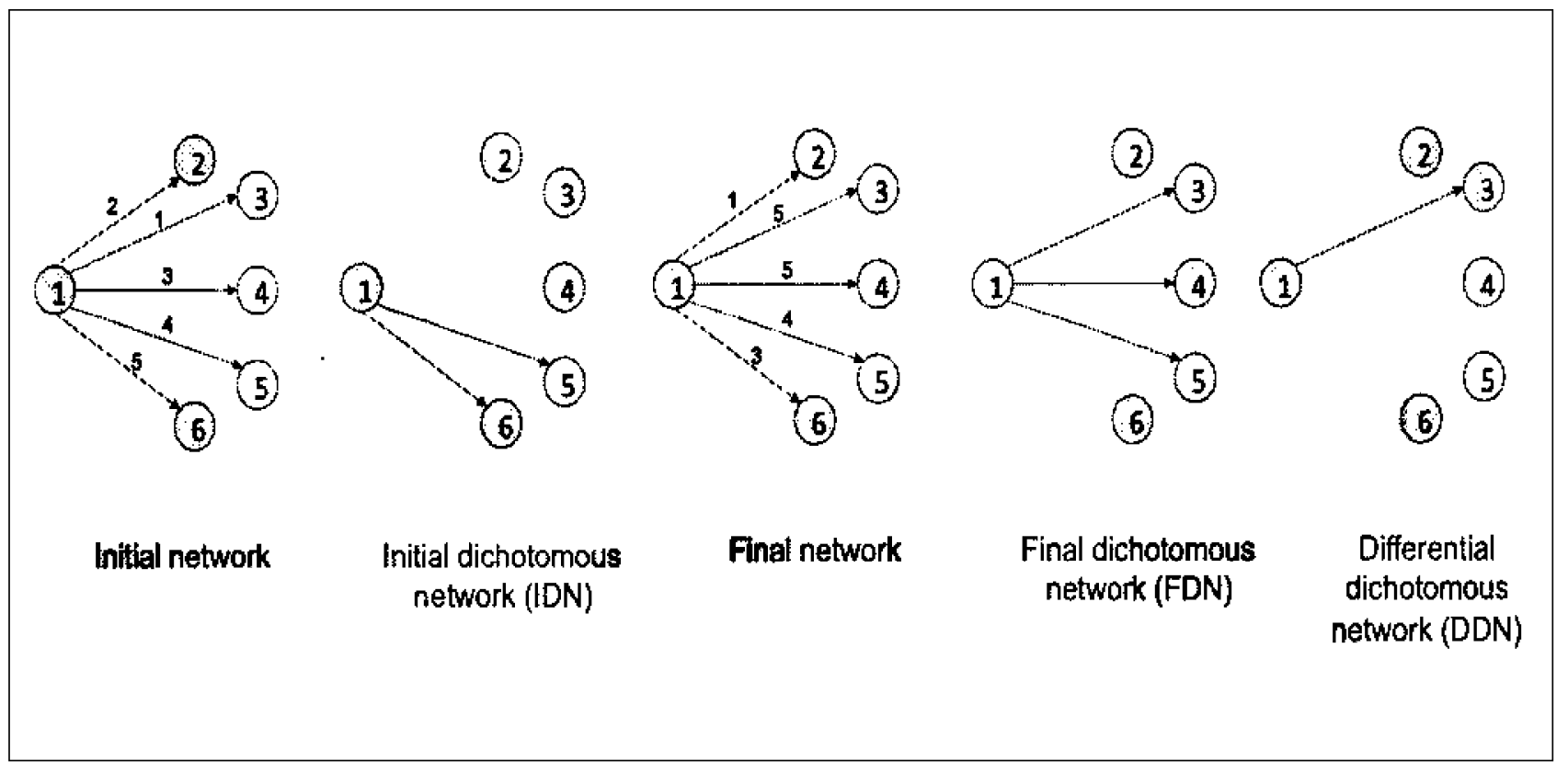

Figure 1. An abstract example of each of the networks used in the study. 
post-questionnaire and the pre-questionnaire is greater than three. The independent variable was the matrix representing the IDN of discussion and generation of new ideas. Table 1 shows the results of the regression analysis for this variable.

This analysis provides significant evidence, $p=0.045$, which is lower than statistical significance $p<0.05$, that the initial network does not have much effect on the generation of new ties (R-squared). The initial network has an influence of only $5.7 \%$ on the DDN. Therefore, we can conclude that the initial network has no influence on the increase of new links in the FDN of discussion and generation of new ideas, discussed later.

On the other hand, a comparison of the dichotomous networks of discussion and generation of new ideas at the start (IDN) and end (FDN) of the course unit (Table 2) reveals that the number of links has increased by $18.5 \%$. Consequently, the density (the number of links per node) for this type of links increases by $16.61 \%$. These two values suggest that this relationship increased significantly as the course unit was taught.

To analyze how the initial social network for discussion and generation of new ideas formed at the start of the course evolved in relation to other network members and group formation as a result of the PDM teaching/learning processes, we calculated how the social network transitivity coefficient, clustering coefficient,

Table 1. Regression Analysis, DDN and IDN for Discussion and Generation of New Ideas ( 81 Students)

\begin{tabular}{|c|c|c|c|c|c|c|}
\hline \multirow[b]{2}{*}{$\begin{array}{l}\text { Dichotomous } \\
\text { network }\end{array}$} & \multicolumn{2}{|c|}{ Analysis of variance } & \multirow[b]{2}{*}{$\begin{array}{c}p \\
\text { (Normal) }\end{array}$} & \multicolumn{2}{|c|}{$\begin{array}{l}\text { Parameter estimates } \\
\text { (normal) }\end{array}$} & \multirow[b]{2}{*}{$P$} \\
\hline & $R$-squared & F-Value & & $\begin{array}{l}\text { Reg. } \\
\text { Coef. }\end{array}$ & Std. Err. & \\
\hline $\begin{array}{l}\text { Discussion and } \\
\text { generation of } \\
\text { new ideas }\end{array}$ & 0.057 & $\infty$ & 0 & 0.238 & 0.120 & 0.045 \\
\hline
\end{tabular}

Table 2. Evolution of the Number of Links, Density, Transitivity, Clustering, and Cohesion Index of the FDN against IDN for Discussion and

Generation of New Ideas

\begin{tabular}{lccccc}
\hline Dichotomous network & $\begin{array}{c}\text { No. of } \\
\text { links }\end{array}$ & Density & Transitivity & Clustering & $\begin{array}{c}\text { Cohesion } \\
\text { Index }\end{array}$ \\
\hline $\begin{array}{l}\text { Discussion and generation } \\
\text { of new ideas (IDN) }\end{array}$ & 200 & 0.062 & 0.06 & 0.061 & 0.497 \\
$\begin{array}{l}\text { Discussion and generation } \\
\text { of new ideas (FDN) }\end{array}$ & 237 & 0.0723 & 0.077 & 0.0876 & 0.574 \\
\hline
\end{tabular}


and cohesion index changed for all 81 students that completed the pre- and postquestionnaires.

The transitivity coefficient is the ratio between the total number of transitive triads and the total number of triads. The network clustering coefficient is calculated by averaging the clustering coefficients of all the network nodes. The clustering coefficient of a node is the quotient of all a node's neighboring nodes and all the possible connections among those neighboring nodes. The cohesion index is the ratio between the existing ties among nodes of the same group and ties among nodes of different groups; that is, a descriptive measure of what the group social network is like. For instance, a high cohesion index means that the individuals mostly have ties with other network members.

The results are shown in Table 2. They indicate that, for the social relationship of idea discussion and generation, the transitivity value increased by $28.33 \%$, the clustering value increased by $43.60 \%$, and the cohesion index increased by $15.5 \%$ by the end of the course unit. These substantial increases suggest that there is a clear tendency to form new transitive ties, groups, and interrelationships among students that generate knowledge as a result of the multiple social interactions taking place during the course unit delivered according to our moderate constructivist e-learning instructional model. Noteworthy in this respect is the influence of good problems that have to be solved by students working in groups as part of the course unit activities. The good problems are a team effort, and the good problem statements are common for all the teams. Common statements facilitate the discussion of ideas inside and outside teams, mainly because instructors are obliged to answer any questions about the statements once every week in a face-to-face class setting, where all the students have access to the questions asked and the instructors' responses.

Based on these results, we can conclude that the relationship of discussion and generation of new ideas among students increases and strengthens from the start to the end of the course unit as a result of the enactment of our teaching/learning method combining a moderate constructivist instructional model with a b-learning approach.

Three of the empirical results resulting from studying the evolution of the social network of discussion and generation of new ideas from the start to the end of the PDM course unit using our teaching/learning method are noteworthy. First, the initial network of discussion and generation of new ideas has hardly any influence $(5.7 \%)$ on the generation of new links in the final network. Second, there was a significant increase in the number (18.5\%) and density (16.61\%) of links in the network of discussion and generation of new ideas from the start to the end of the course unit, as a result of course teaching. Third, the transitivity, clustering, and cohesion indices increase considerably as a result of the multiple social interactions taking place throughout the course unit. On this ground, we believe that knowledge building has increased, leading to better student academic outcomes, as described below. 


\section{ANALYSIS OF NETWORKS OF DISCUSSION AND GENERATION OF NEW IDEAS WITH RESPECT TO ACADEMIC ATTAINMENT}

We have analyzed the academic outcomes of all 81 students against the evolution of the indegree of the nodes of the dichotomous networks for the social relationship of discussion and generation of new ideas from the start (IDN) to the end (FDN) of the course unit. From this analysis, we have found that the nodes whose indegree decreases from IDN to FDN belong to students whose average final grade is 4.30 out of 10 . The average grade for nodes (students) whose indegree is more or less the same from IDN to FDN is 4.7. The nodes whose indegree increases from 1 to 3 have a mean grade of 5.2. Finally, the average grade of students whose indegree increases by more than 3 links is quite a lot higher (6.8). Table 3 shows these results that corroborate the fact that the discussion and generation of new ideas has a significant impact on student academic outcomes.

\section{EVOLUTION OF THE INFLUENCE OF SOCIAL NETWORKS ON THE DISCUSSION OF NEW IDEAS}

We have seen that, from the constructivist viewpoint, learning is built as part of a process of social debate that generates meaning. Learning is inherently a process of social dialogue (Jonassen et al., 1999). The process is mediated by conceptual tools produced by earlier social processes. The discussion and generation of new ideas is then essential for generating knowledge and learning, as is the setup of the social network in which such discussions take place.

In a multi-relational reality, the discussion and generation of new ideas is promoted, limited, or conditioned by other underlying relationships. To analyze this claim, we study the influence that friendship, communication, advice-seeking, and trust networks have on the relationship of discussion and generation of new ideas. To do this, we compare the IDN and FDN for each social relationship to observe how the network evolved as a result of the delivery of the PDM course unit using our teaching/learning method.

Table 3. Academic Outcomes of the Dichotomous Networks of Discussion and Generation of New Ideas Depending on Node Indegrees

\begin{tabular}{lcccc}
\hline & \multicolumn{2}{c}{$\begin{array}{c}\text { Academic outcomes with respect to the evolution } \\
\text { of node indegrees (students) }\end{array}$} & \\
\hline $\begin{array}{l}\text { Variation of the node } \\
\text { indegrees from IDN to FDN }\end{array}$ & $<0$ & 0 & +1 to 3 & $>3$ \\
\begin{tabular}{l} 
Average final grade of nodes \\
\hline
\end{tabular} & 4.30 & 4.7 & 5.2 & 6.8 \\
\hline
\end{tabular}


Tables 4 and 5 show, respectively, the coefficients of the regression equation from the start to the end of the course unit.

The regression equation illustrates the evolution of the social relationship of discussion and generation of new ideas (dependent variable) with respect to the other selected social relationships of friendship, communication, advice-seeking, and trust (independent variables) based on their respective IDNs and FDNs.

\section{CONCLUSIONS AND FUTURE WORK}

This article presents a study of the influence of the social relationships among students after deploying our moderate constructivist instructional model with a blend-learning approach. This study was motivated by the belief that this instructional model encourages knowledge building and learning through social relationships among students. The goal of this study was to find out why this teaching/learning model improves student academic outcomes and increases their interest in what they are studying, as we have shown in earlier studies. This study was run during the 2011/12 academic year on students of the 3rd-year program development models (PDM) course unit, taught as part of the accredited 5-year informatics engineering degree.

After a social network analysis of five relevant student relationships (friendship, communication, advice-seeking, trust, discussion, and generation of new ideas) during the course unit, we have arrived at three major findings, outlined in Figure 2.

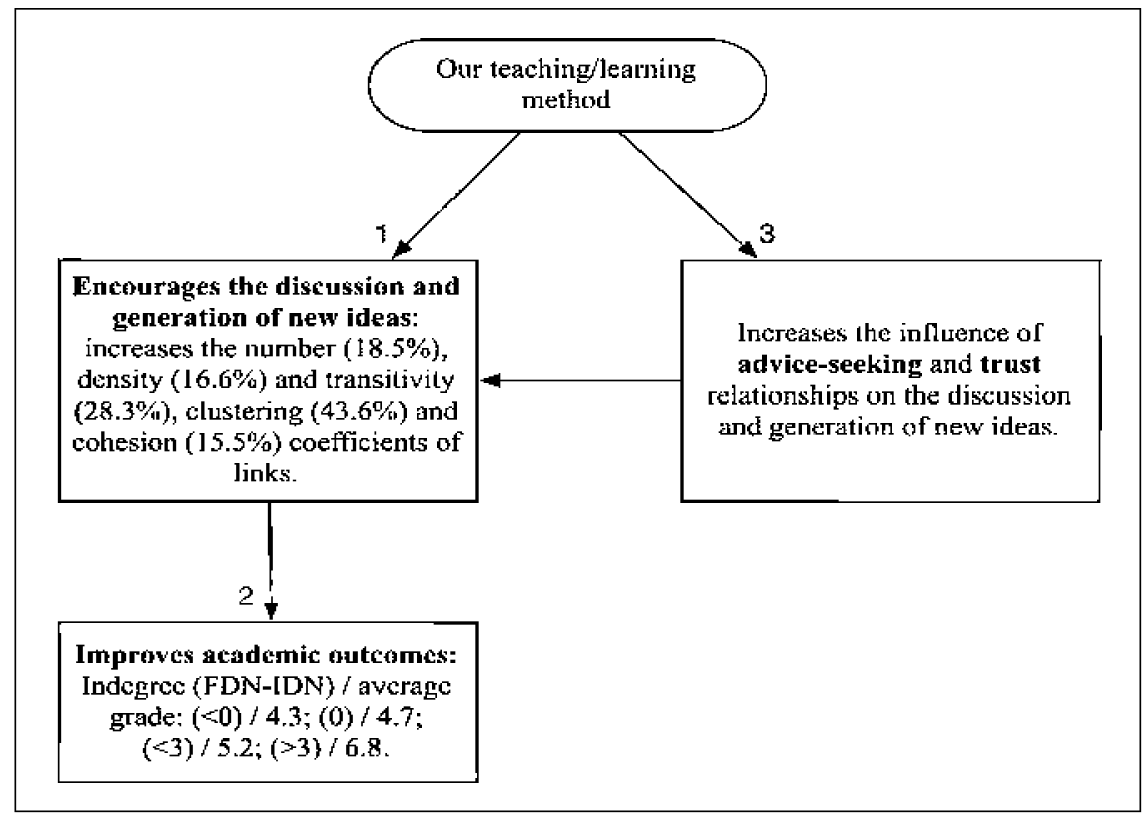

Figure 2. Diagram of relationships between the reported findings. 
Table 4. Coefficients of the Regression Equation of the IDN for Discussion and Generation of New Ideas with Respect to the Other IDNs for the PDM Course Unit

\begin{tabular}{|c|c|c|c|c|c|c|}
\hline \multicolumn{7}{|c|}{ Analysis of Variance } \\
\hline$R$-square & $F$-value & $P($ normal) & & Obs.) & $P(==$ Obs. $)$ & $P(<=$ Obs. $)$ \\
\hline 0.947 & 26522.138 & 0 & & 05 & 0 & 0.245 \\
\hline \multicolumn{7}{|c|}{ Parameter Estimates (QAP) } \\
\hline & Observed & $\begin{array}{c}\text { Expected } \\
\text { (mean) }\end{array}$ & Std. Dev. & $P(>=$ Obs. $)$ & $P(==$ Obs $)$ & $P<=$ Obs.) \\
\hline Friendship & 0.281 & -0 & 0.004 & 0 & 0 & 1 \\
\hline Communication & 0.384 & -0 & 0.004 & 0 & 0 & 1 \\
\hline Advice-seeking & 0.029 & -0 & 0.003 & 0 & 0 & 1 \\
\hline Trust & 0.292 & -0 & 0.004 & 0 & 0 & 1 \\
\hline
\end{tabular}


Table 5. Coefficients of the Regression Equation of the FDN Discussion and Generation of New Ideas Network with Respect to the Other FDNs for the PDM Course Unit

\begin{tabular}{|c|c|c|c|c|c|c|}
\hline \multicolumn{7}{|c|}{ Analysis of Variance } \\
\hline$R$-square & $F$-value & $P($ normal) & & Obs.) & $P(==$ Obs. $)$ & $P(<=$ Obs. $)$ \\
\hline 0.901 & 13426.66 & 0 & & & 0 & 0.25 \\
\hline \multicolumn{7}{|c|}{ Parameter Estimates (QAP) } \\
\hline & Observed & $\begin{array}{c}\text { Expected } \\
\text { (mean) }\end{array}$ & Std. Dev. & $P(>=$ Obs. $)$ & $P(==$ Obs $)$ & $P<=$ Obs.) \\
\hline Friendship & 0.096 & 0 & 0.005 & 0 & 0 & 1 \\
\hline Communication & 0.220 & 0 & 0.005 & 0 & 0 & 1 \\
\hline Advice-seeking & 0.336 & -0 & 0.005 & 0 & 0 & 1 \\
\hline Trust & 0.319 & 0 & 0.005 & 0 & 0 & 1 \\
\hline
\end{tabular}


First, we have shown in the section concerning the influence of the proposed b-learning approach on the discussion and generation of new ideas that the enactment of this learning method increases and strengthens social relationships among students. Effectively, whereas the initial network of discussion and generation of new ideas has hardly any influence $(5.7 \%)$ on the generation of new links in the final network, there was a significant increase in the number of links (18.5\%) and density $(16.6 \%)$ in the final network from the start to the end of the course unit. This finding, illustrated in Figure 2 (box 1), suggests then that learning interactions among students play a key role by prompting students to choose partners with which to discuss new ideas during the course unit. Knowledge building pedagogy focusing on the advancement of idea improvement through an iterative discussion process should account for these results (Bereiter \& Scardamalia, 2006).

Second, our findings also point to a remarkable influence of the discussion and generation of new ideas among students on their academic attainment. The students more often named as partners with which to discuss new ideas had better academic outcomes (with an average grade of up to 6.80 out of 10 ) than students who were less often named (average grade of 4.30). This is illustrated in Figure 2 (box 2).

Third, authors have explained knowledge building as a result of embeddedness and tie strength (Uzzi \& Lancaster, 2003) or structural holes (Burt, 2004) in people social networks. This research expands the approach by studying the effect size of key relationship types among students on the discussion and generation of new ideas. The research provides evidence of how the idea discussion relationship builds on other relationships like trust and advice-seeking. This is illustrated in Figure 2 by the arrow linking box 3 to box 1 .

Although we conducted this study according to a strict methodology, it is subject to some limitations or threats that have to be taken into account when interpreting the results. First, the study was conducted over a single academic year and the measures were subjective. Therefore, the statistical results might be biased. Nevertheless, we consider that the sample size (81 students) and homogeneity of the academic background of the students enrolled in the course unit are sufficient to minimize this threat. Second, we have studied the main social relationships among students referenced in the literature as being likely to influence knowledge building, although there could be other social relationships that we have not taken into account.

The results lead us to conclude that in order to improve the academic outcomes of students, we should improve the learning processes of our teaching/learning method that promote the social relationships of advice-seeking and trust among students, as they have a positive impact on the discussion and generation of new ideas and, ultimately, on knowledge building and learning. These relationships should be appraised and promoted throughout course deployment, as weak trust and weak advice-seeking networks among students could otherwise be obstacles to individual and obviously collective learning. 
Cross, Parker, and Borgatti (2002) have listed some tips on how to promote the social relationships of advice-seeking: a) skill profiles and communities of practice to ascertain who knows what, b) e-mail lists and forums for easing access to everyone, c) peer reviews to promote cognitive engagement, and d) a safe environment where students can build trust and are more willing to share information and knowledge with peers. We believe that skill profiles and communities of practice to ascertain who knows what and peer reviews to promote cognitive engagement are two lines worth researching in our educational model, as the others are already being applied.

The second most important social relationship to be promoted in our teaching/ learning model to improve academic outcomes is trust. So, it is important to address the question: whom do students trust? Teachers should be concerned about how to foster and monitor initial trust during the deployment of course tasks. Easing access to specific information in student profiles enhances initial trust. Rusman, Van Bruggen, Sloep, and Koper (2010) studied which information is important for trustworthiness assessments in the initial phase. They built the TrustWorthiness ANtecedents (TWAN) schema to determine which information is relevant for team members assessing others' trustworthiness. Other authors concerned with organizational trust (Abrams, Cross \& Levin, 2003) propose useful behaviors and practices to nurture and promote interpersonal trust in knowledge creation and sharing contexts. So, we propose to include a student guide in our teaching/learning practice to address the trust question. This guide should provide information about their peers based on TWAN schema, a description of good behaviors, and organizational rules that foster trust. Furthermore, our research has unidimensionally conceptualized trust ties in social networks, making no distinctions between affect-based and cognition-based trust. However, these types of trust may lead to different knowledge building outcomes (Chua et al, 2008; Levin \& Cross, 2004; McAllister, 1995). Cognition-based trust is based on competence and reliability, affect-based trust arises from emotions. While affect-based trust is higher in friendship networks or in networks with densely embedded ties, cognition-based trust is higher in advice networks, and embeddedness has no effect. In future research, therefore, we intend to study how affect-based and cognition-based trust accounts for idea exchange and knowledge building in learning contexts.

Disentangling how different types of trust, advice-seeking, and new ideas discussion interact in online and face-to-face contexts is an exciting challenge for future research. We expect that the study of these key relationships in student social networks will provide useful insights for improving knowledge building when teaching courses.

\section{REFERENCES}

Abrams, L. C., Cross, R. L, \& Levin, D. Z. (2003). Nurturing interpersonal trust in knowledge sharing networks. Academy of Management Executive, 17(4), 64-77. 
Alonso, F., Lopez, G., Manrique, D., \& Viñes, J. M. (2008). Learning objects, learning objectives and learning design. Innovations in Education and Teaching International, 45(4), 389-400.

Alonso, F., Manrique, D., Martínez, L., \& Viñes, J. M. (2011). How blended learning reduces underachievement in higher education: an experience in teaching computer sciences. IEEE Transactions on Education, 54(3), 471-478.

Alonso, F., Manrique, D., \& Viñes, J. M. (2009). A moderate constructivist e-learning instructional model evaluated on computer specialists. Computers \& Education, 53(1), $57-65$.

Amabile, T. M. (1983). The social psychology of creativity: A componential conceptualization. Journal of Personality and Social Psychology, 45(2), 357-376. doi: 10.1037/ 0022-3514.45.2.357

Amabile, T. M., Conti, R., Coon, H., Lazenby, J., \& Herron, M. (1996). Assessing the work environment for creativity. Academy of Management Journal, 39(5), 1154-1184.

Anderson N. H. (1996). A functional theory of cognition. Hillsdale, NJ: Erlbaum.

Baldwin, T. T., Bedell, M. D., \& Johnson, J. L. (1997). The social fabric of a team-based MBA program: Network effects on student satisfaction and performance. Academy of Management Journal, 40(8), 1369-1397.

Bereiter, C., \& Scardamalia, M. (2006) Knowledge building. Theory, pedagogy, and technology. In K. Sawyer (Ed.), Cambridge Handbook of Learning Sciences (pp. 97-118). New York, NY: Cambridge University Press.

Bradach, J. L., \& Eccles, R. G. (1989). Price, authority, and trust: From ideal types to plural forms. In W.R. Scott (Ed.), Annual Review of Sociology (Vol. 15, pp. 97-118). Palo Alto, CA: Annual Review.

Bransford, J. D., Sherwood, R. D., Hasselbring, T. S., Kinzer, C. K., Williams, S. M. (1990). Anchored instruction: why we need it and how technology can help. In D. Nix \& R. Sprio (Eds.), Cognition, education and multimedia. Hillsdale, NJ: Erlbaum Associates.

Brass, D. J. (1984). Being in the right place: A structural analysis of individual influence in an organization. Administrative Science Quarterly, 29, 518-539. doi: 10.2307/2392 937

Burt, R. S. (2004). Structural holes and good ideas. The American Journal of Sociology, 110 (2), 349-399. doi: $10.1086 / 421787$

Burt, R. S. (2005). Brokerage and closure: An introduction to social capital. Oxford, England: Oxford University Press.

Cho, H., Gay, G., Davidson, B., \& Ingraffea, A. (2007). Social networks, communication styles, and learning performance in a CSCL community. Computers \& Education, 49(2), 309-329. doi: 10.1016/j.compedu.2005.07.003

Chua, R. Y. J., Ingram, P., \& Morris, M. (2008). From the head and the heart: Locating cognition and affect-based trust in managers' professional networks. Academy of Management Journal, $51(3), 436-452$.

Cohen, D., \& Prusak, L. (2001). In good company: How social capital makes organizations work. Boston, MA: Harvard Business Press.

Cross, R., Parker, A., \& Borgatti, S. P. (2002). A bird's-eye view: Using social network analysis to improve knowledge creation and sharing. Technical Report, IBM Institute for Business Value.

Donovan, M. S., Donovan, J. D. Bransford, J. W., \& Pellegrino (1999). How people learn: Bridging research and practice. Washington, DC: National Research Council Committee Learning Resources and Educational Practice. 
Doise W., \& Mugny G. (1984). The social development of the intellect. Oxford, England: Pergamon Press.

El-Deghaidy H., \& Nouby A. (2008). Effectiveness of a blended e-learning cooperative approach in Egyptian teacher education program. Computers \& Education 51(3), 988-1006. doi: 10.1016/j.compedu.2007.10.001

Ellis, H. J. C. (2007). An assessment of a self-directed learning approach in a graduate web application design and development course. IEEE Transactions on Education, 50(1), 55-60. doi: 10.1109/TE.2006.888907

Garrison D. R., \& Kanuka H. (2004). Blended learning: Uncovering its transformative potential in higher education. Internet in Higher Education, 7(2), 95-105. doi: 10.1016/ j.iheduc.2004.02.001

Good T. L., \& Brophy J. E. (1990). Educational psychology: A realistic approach (4th ed.).White Plains, NY: Longman.

Granovetter, M.S. (1985). Economic action and social structure: The problem of embeddedness. American Journal of Sociology, 91 (3), 481-510.

Harasim, L., Hiltz, S. R., Teles, L., \& Turoff, M. (1995). Learning networks: A field guide to teaching and learning online. Cambridge, MA: The MIT Press.

Haythornthwaite, C. (2001). Exploring multiplexity: Social network structures in a computer-supported distance learning class. The Information Society, 17(3), 211-226. doi: $10.1080 / 01972240152493065$

Haythornthwaite, C. (2002). Building social networks via computer networks: Creating and sustaining distributed learning communities. In K. Renninger \& W. Shumar (Eds.), Building virtual communities: learning and change in cyberspace (pp. 252-259). Cambridge, England: Cambridge University Press.

Haythornthwaite, C. (2008). Learning relations and networks in web-based communities. International Journal of Web Based Communities, 4(2), 140-158. doi: 10.1504/ IJWBC.2008.017669

Hoic-Bozic, N. Mornar, V., \& Boticki, I. (2009). A blended learning approach to course design and implementation, IEEE Transactions on Education, 52(1), 19-30. doi: 10.1109/TE.2007.914945

Huisman, J., Kaiser, F. \& Vossensteyn, H. (2003). The relations between access, diversity and participation: Searching for the weakest link? In M. Tight (Ed.), Access and evaluation: International perspectives in higher education research (pp. 1-28). London: Elsevier.

Ibarra, H. (1995). Race, opportunity, and diversity of social circles in managerial networks. Academy of Management Journal, 38(3),673-703.

Ibarra, H., \& Andrews, S. B. (1993). Power, social influence, and sense-making: Effects of network centrality and proximity on employee perceptions. Administrative Science Quarterly, 38(2), 277-303.

Johnson, D. W., \& Johnson, R. T. (1999). Learning together and alone: Cooperative, competitive and individualistic learning (5th ed.). Needham Heights, MA: Allyn and Bacon.

Jonassen D. H. (1991). Objectivism versus constructivism: Do we need a new philosophical paradigm? Educational Technology Research and Development, 39(3), 5-14. doi: 10.1007/BF02296434

Jonassen, D. H., Peck K. L., \& Wilson, B. G. (1999). Learning with technology: A constructivist perspective (pp. 2-11). Upper Saddle River, NJ: Merril/Prentice Hall. 
Karagiorgi, Y., \& Symeou, L. (2005). Translating constructivism into instructional design: Potential and limitations. Educational Technology \& Society, 8(1), 17-27.

Lange, D. D., Agneessens, F., \& Waege, H. (2004). Asking social network questions: A quality assessment of different measures. MetodološkiZvezki, 1(2), 351-378.

Leenders, R., Engelen, V. J., \& Kratzer, J. (2003). Virtuality, communication and new product team creativity: A social network perspective, Journal of Engineering and Technology Management, 20, 69-92.

Levin, D. Z., \& Cross, R. 2004. The strength of weak ties you can trust: The mediating role of trust in effective knowledge transfer. Management Science, 50(11), 1477-1490. doi: $10.1287 / \mathrm{mnsc} .1030 .0136$

Lincoln, J., \& Miller, J. (1979). Work and friendship ties in organizations: A comparative analysis of relational networks. Administrative Science Quarterly, 24,181-199.

McAllister, D. J. (1995). Affect- and cognition-based trust as foundations for interpersonal cooperation in organizations. Academy of Management Journal, 38(1), 24-59.

Michell, L. (2001). E-learning methods offer a personalized approach. InfoWorld, 174-185.

Moreno, L., Gonzalez, C., Castilla, I., Gonzalez, E., \& Sigut, J. (2005). Applying a constructivist and collaborative methodological approach in engineering education. Computers \& Education, 49, 891-915. doi: 10.1016/j.compedu.2005.12.004

Nahapiet, J., \& Ghoshal, S. (1998). Social capital, intellectual capital, and the organizational advantage. Academy of Management Review, 23(2), 242-266.

NetMiner. (2012). http://www.netminer.com/index.php

Nonaka, I., \& Konno, N. (1998). The concept of BA: Building a foundation for knowledge creation. California Management Review.40(3), 40-54.

Palloff, R., \& Pratt, K. (1999). Building learning communities in cyberspace. Effective strategies for online classroom. San Francisco, CA: Jossey-Bass.

Palloff, R., \& Pratt, K. (2003). The virtual student: A profile and guide to working with online learners. San Francisco, CA: Jossey-Bass.

Perry-Smith, J. E. (2006). Social yet creative: The role of social relationships in facilitating individual creativity. Academy of Management Journal, 49(1), 85-101.

Perry-Smith, J. E., \& Shalley, C. E. (2003). The social side of creativity: A static and dynamic social network perspective. Academy of Management Review, 28(1), 89-106.

Rusman, E., Van Bruggen, J., Sloep, P., \& Koper, R. (2010). Fostering trust in virtual project teams: Towards a design framework grounded in a trustworthiness antecedents (TWAN) schema. International Journal of Human-Computer Studies, 68(11), 834850. doi: 10.1016/j.ijhcs.2010.07.003

Scardamalia, M. (2002). Collective cognitive responsibility for the advancement of knowledge. In B. Smith (Eds.), Liberal education in a knowledge society (pp. 67-98). Chicago, IL: Open Court.

Scardamalia, M., \& Bereiter, C. (2003). Knowledge building. In Encyclopedia of education (2nd ed., pp. 1370-1373). New York, NY: Macmillan Reference.

Skerlavaj, M., Dimovski, V., Mrvar, A., \& Pahor, M. (2010). Intra-organizational learning networks within knowledge-intensive learning environments. Interactive Learning Environments, 18(1), 39-63. doi: 10.1080/10494820802190374

Sparrowe, R. T., Liden, R. C., \& Kraimer, M. L. (2001). Social networks and the perfor mance of individuals and groups. Academy of Management Journal, 44(2), 316-325.

Stahl G. (2004). Building collaborative knowing: elements of a social theory of CSCL. In J.-W. Strijbos, P. Kirschner \& R. Martens (Eds.), What we know about CSCL and 
implementing it in higher education (pp. 53-86). Boston, MA: Kluwer Academic Publishers.

Stahl, G. (2005). Group cognition in computer-assisted collaborative learning. Journal of Computer-Assisted Learning, 21 (2), 79-90. doi: 10.1111/j.1365-2729.2005.00115.x

Thorne K. (2003). Blended learning: how to integrate online and traditional learning. Hillsdale, NJ: Kogan Page.

Uzzi, B., \& Lancaster, R. (2003). Relational embeddedness and learning: The case of bank loan managers and their clients. Management Science, 49 (4), 383-399.

Vygotsky, L.S. (1978). Mind in society: The development of higher psychological processes. Cambridge, MA: Harvard University Press.

Wasserman, S., \& Faust, K. (1994). Social Network Analysis: Methods and Applications (pp. 1-27). Cambridge: Cambridge University Press.

Woodman, R. W., Sawyer, J. E., \& Griffin, R. W. (1993). Toward a theory of organizational creativity. The Academy of Management Review, I8(2), 293-321.

Zhou, J. (1998). Feedback valence, feedback style, task autonomy, and achievement orientation: Interactive effects of creative performance. Journal of Applied Psychology, 83, 261-276.

Zhou, J. (2008). Promoting creativity through feedback. In J. Zhou \& C. E. Shalley (Eds.), Handbook of organizational creativity. New York, NY: Lawrence Erlbaum Associates.

Zhou, J., \& George, J. M. (2003). When the presence of creative coworkers is related to creativity: Role of supervisor close monitoring, developmental feedback, and creative personality. Journal of Applied Psychology, 88(3), 413-422. doi: 10.1037/0021-9010. 88.3.413 